\title{
Training implications of community-oriented psychiatry
}

\section{K. Linsley, R. Slinn, R. Nathan, L. Guest \& H. Griffiths}

Over the past 20-30 years psychiatry has gradually moved from predominantly hospital-based care to care in the community. Community psychiatry embraces a variety of definitions: it may describe the practice setting, the population served or the philosophy of illness and treatment (Johnston et al, 1995). In discussing the training implications of this shift towards community models of psychiatric care, we will not consider a separate discipline of 'adult community psychiatry'. We believe that nearly all psychiatric specialities now involve substantial elements of work outside the hospital, and we therefore contend that the new skills, knowledge and attitudes required to meet the challenge of providing both hospital- and community-based care are pertinent to all trainees. Furthermore, the development of these are essential if the consultant of the future is to provide the safe, effective and sustainable service to those with complex mental health needs detailed in the recent National Service Framework (NSF) for Mental Health (Department of Health, 1999). We will also not attempt specifically to assess the merits of the move to community psychiatry, which may be subject to a separate debate.

This article is based on general discussions by the Collegiate Trainees Committee of the Royal College of Psychiatrists and specific ideas generated within the working party. Literature was identified by searching the Medline and Psychlit databases using the keywords TRAINING and COMMUNITY PSYCHIATRY. Feedback on an early draft was obtained from the General Adult and Community Faculty Executive Committee.
We hope that this article will stimulate discussion within training schemes and assist educational supervisors to review the training needs of trainees and identify potential areas for change.

\section{Knowledge, skills and attitude required}

\begin{abstract}
The knowledge and skills required for communityoriented psychiatry are extensive, and here we will highlight the key areas that trainees need to address. An important concept is that good community psychiatry is merely an extension of good general psychiatric practice. Some authors view the separation of hospital and community as artificial (Johnston et al, 1995), and it could be argued that the crucial training requirement is the fostering of appropriate attitudes to enable greater appreciation of the collaboration required between in-patient and community teams and of their respective roles.
\end{abstract}

\section{Skills}

Trainees may be asked to see patients in out-patient departments, general practitioners' (GPs') surgeries, supported accommodation (including grouped homes and hostels) and patients' own homes. They should feel comfortable seeing patients in these varying settings. The skills to assess at home

Keith Linsley is a consultant in general adult and community psychiatry at the County Hospital, North Road, Durham DH1 4ST (e-mail: keith.linsley@cddpsnhs.fsnet.co.uk). He has interests in liaison psychiatry, suicide research and the training needs of general adult psychiatrists. Rebecca Slinn is a member of the Collegiate Trainees Committee and is currently a specialist registrar in general and old age psychiatry at Southmead Hospital, Bristol. Rajan Nathan is a specialist registrar in forensic psychiatry at the Scott Clinic, Merseyside and a member of the Collegiate Trainees Committee. Louise Guest is a consultant in general adult psychiatry, working within a community mental health team in Sutton, Surrey, and an honorary senior lecturer at the Department of Community Psychiatry, St George's Hospital Medical School, London. Hugh Griffiths is a consultant psychiatrist and Medical Director for Northumberland Mental Health Trust, Honorary Clinical Lecturer at the School of Neurosciences, University of Newcastle-upon-Tyne and Medical Director for the Northern Centre for Mental Health. 
someone who has severe mental illness (SMI) and to develop rapport not only with the patient but also with the carer(s) are particularly important (see NSF standard 6, Department of Health, 1999). Awareness of approaches to reduce the burden of care on carers is necessary (Vaddadi, 1997).

Allied to these skills is the ability, in a community setting, to stabilise an acutely disturbed patient, to determine who cannot be managed in the community and to negotiate an admission or arrange Mental Health Act assessment. Trainees should also develop their skill in taking an abbreviated focused history and carrying out a mental state examination. The management of their own safety and that of carers is a vital skill, and trainees should never feel that they have to place themselves or others at risk. Risk assessment in community settings, where less information or support are available than in an inpatient setting, is often more demanding. Trainees must gain the confidence to avoid allowing the increasing pressure on acute beds to affect their clinical judgement. They must learn to manage acute drug changes at home, understand when to admit or to use day hospital facilities for some changes (e.g. when initiating clozapine treatment), especially for those with SMI or those on polypharmacy. Training must embrace the assessment of the complex needs of 'displaced' long-stay patients, including those in supported accommodation, and enable effective support of the care staff. Trainees must therefore be given time to accompany senior colleagues to witness the management of such situations (see Box 1).

As psychiatric services move increasingly into the community there is a danger that case-loads will

Box 1 Key requirements for trainees

Trainees should have adequate supervised exposure to:

- home assessments

- Mental Health Act assessments

- joint assessments with other members of the multi-disciplinary team

- day hospitals (acute and rehabilitation)

- assertive outreach methods of working with clients

- crisis intervention teams

- primary care liaison

Specialist attachment to units for the homeless, accident and emergency liaison and grouped home reviews should also be considered expand beyond our current capacity to manage them. Efficient case-load management skills must be developed. One often-neglected area in training is the skill required to know when and how to discharge a patient from review.

\section{Knowledge}

Community psychiatry involves various forms of treatment using a number of service delivery models. Trainees need to appraise the literature on these models and their effectiveness (see NSF standards 4 and 5, Department of Health, 1999; Muijen, 1993; Tyrer \& Creed, 1995). The function of innovative service models and interventions should be understood, particularly their role in preventing admission, facilitating early discharge and addressing functional improvement. One such model is assertive community treatment (ACT). This incorporates assertive outreach, case sharing, small case-loads, an active team leader, dedicated psychiatric involvement, 24hour cover and community-based services (Marshall \& Creed, 2000). An ACT team attempts to provide all the psychiatric and social care that clients require (Marshall \& Lockwood, 2000).

At a time of acute mental illness some patients benefit from crisis intervention (acute home treatment and acute day hospital services) (for a review of this approach see, e.g., Bancroft, 1986). The 'crisis intervention team' is usually multi-disciplinary and may be available 24 hours a day. It advocates prompt detection of any exacerbation of SMI, followed by swift, time-limited, intense treatment delivered in a community setting. Treatment usually involves a combination of medication, counselling or therapy, practical help with living skills and support for family members. After the crisis has been stabilised sufferers are introduced to other models of care. It should be recognised that admission may be required (Joy et al, 2000).

The appreciation of psychosocial interventions may involve a change in mind-set, from traditional medical syndromes to an individual symptom approach, and a focus on vulnerabilities and environmental stressors, as well as on symptoms (Wykes et al, 1998). Similarly, early intervention in psychosis entails an ability to work closely with patients (Tarrier et al, 1998) in a way that may be novel to trainees who have witnessed a more paternalistic medical approach.

Account must be taken of the debate concerning the limitations of new services (e.g. Dedman, 1993; Marshall, 1996). Attention is drawn to research findings that focus on finite periods of interventions with motivated staff and studies that may exclude those with comorbidity (such as drug and alcohol 
misuse). Trainees' experience would therefore be enhanced by visits to centres that provide these services.

Community-oriented psychiatry usually involves working within the framework of a multi-disciplinary team (MDT). This can be a difficult transition to make and the skills to manage the relationships involved may have to be learned. An awareness of the roles of community psychiatric nurses, social workers, occupational therapists, psychologists and support workers in relation to acute treatment, relapse prevention and the spectrum of psychosocial interventions is essential. Leadership is likely to be required and it is important to recognise that this is earned, must be worked at and should not be taken for granted. Community psychiatrists of the future will need to acquire not only the clinical skills but also the managerial skills involved in complex service change (O'Grady, 1996).

Trainees must become familiar with the theory and practice of the Care Programme Approach, which has been reviewed in this journal before (Kingdom, 1994). They might be given the opportunity to take on key-worker responsibilities, under supervision, in which case they will need the same access to administrative support as other members of the team.

Trainees must recognise the relationship between adverse social factors, such as homelessness, and a high degree of associated mental ill health and appreciate how alleviating social disadvantage can positively influence health. This will involve skills in liaising with local services and voluntary agencies, and experience working in these areas should be valued.

\section{Attitudes}

The development of appropriate attitudes is fundamental: without them the use of the skills and knowledge acquired will be severely compromised. Perhaps we should first recognise that community psychiatry is of benefit to the majority of patients, but that it sets challenges for psychiatrists, such as supervision of risk and medication concordance. The Sainsbury Centre for Mental Health (1997) describes how traditional training for mental health professionals has focused on 'cure' rather than 'care' and states that this is no longer appropriate for work in the community with people with SMI. Trainees must learn to appreciate the benefits of setting realistic goals for the long-term ill with severe disabilities. As medical education shifts from hospital to community, the emphasis changes from disease to prevention, from symptoms to quality of life and from control to collaboration (Johnston et al,
1995). Hence, our understanding of the psychiatrist's role must be revised accordingly, particularly recognising our increasing part in rehabilitation. For this to happen, a willingness to work with others (families, MDT staff, etc.) should be cultivated and trainees should be careful to avoid working on the periphery of community mental health teams (CMHTs) as what Factor et al (1988) call 'prescription writers'. An openness to explore a variety of opinions from others involved in patient care (including the patient) is desirable, as is a willingness to evaluate one's own professional work within a CMHT. An attitude of partnership not paternalism should prevail, with a readiness to be the patients' advocate and to fight for resources.

Trainees should develop a flexible attitude; for example, psychiatrists cannot assume that they will always be in charge (Johnston et al, 1995) or always be right in their judgements, and they should be sensitive to cultural values. Communication is important, and an attitude of sharing relevant information should be fostered, especially in view of the recommendations of recent inquiries. Access to notes is sometimes difficult in the community, especially if several professionals visit a hostel or home. To ensure confidentiality it is undesirable to keep notes at the patient's place of residence. Imagination may be required to circumvent these problems, and MDT meetings might prove to be helpful here.

Dispersed sites and community buildings separate from in-patient facilities make it difficult to meet peers, see supervisors and attend teaching sessions. Time management therefore becomes an essential skill to acquire, as does an attitude of personal accountability. Trainees and supervisors should not leave other staff (such as in-patient nurses and secretaries) unsupported, and may therefore need to carry mobile phones and pagers. Individuals' whereabouts should also be known for reasons of safety, and bravado should not be a deterrent to requesting a joint assessor or carrying a personal alarm.

Trainees should also be exposed to primary care liaison, particularly to learn how to manage the sometimes conflicting demands of GPs' expectations and the pressures of dealing with SMI. Appreciation of the epidemiology of mental disorders in the community would help this process. The importance of working with primary care is recognised in NSF standards 2 and 3 (Department of Health, 1999).

Finally, there is a need to value more highly the role of community-oriented psychiatry both within and outwith our profession. Action to change attitudes might include learning how to enhance public education and deal with stigma (see NSF standard 1). 


\section{Current deficiencies in training}

A recent survey of newly appointed consultants in general and old age psychiatry highlighted three deficient areas in specialist registrar (SpR) training programmes: general management, personal management and information technology (Haddad \& Creed, 1996). The Sainsbury Centre for Mental Health (1997) recommends that the College should enhance the training of psychiatrists in management, clinical leadership and team working.

Muijen (1993) highlights the need to learn about and appraise different models of care and types of intervention and to understand how assessment procedures within the community are different and require greater flexibility. One recommendation is that training should be thoroughly revised to target new skills, experiences and attitudes. Specifically, training should include experience of a range of interventions, knowledge of other disciplines and organisations (including inter-disciplinary training) and intensive clinical community experience.

The Sainsbury Centre for Mental Health (1997) believes that there is an urgent need to raise awareness of mental health in primary care, to plan for the movement of staff into community settings and to ensure that training is focused on the community. However, it also recommends the development of all staff in in-patient settings. Trainees must be reminded of the importance of inpatient services and of managing the transition between in-patient and community care. It is significant that the Centre found psychiatrists to have the highest level of emotional exhaustion of all CMHT workers. An analysis of concerns of consultant general psychiatrists (Kennedy \& Griffiths, 2000) found that the major problems facing them included pressures of workload, role ambiguity, lack of influence and inadequate career management. One could argue that the move to communityoriented psychiatry has been one of the greatest contributions to these difficulties and that training has failed to address them. This should therefore focus trainees' thinking to how to confront these issues if the development and delivery of a highquality service is to remain sustainable.

Recent discussion with local SpRs (unpublished: further details available from K.L. upon request) found that one of the most difficult apects of the transition from senior house officer (SHO) to SpR was to lose the image of the 'ward doctor'. This suggests that training currently does not place enough emphasis on involving SHOs in community work. SHO training lasts about the same length of time as SpR training. Thus, reserving community experience until $\mathrm{SpR}$ grade substantially reduces the overall exposure of trainees to communityoriented psychiatry. More important, it delays their understanding of their future role within a mental health service and reduces their ability to modify training experiences accordingly. It may particularly impede the development of appropriate attitudes towards community-based approaches.

The current level of training in communityoriented psychiatry is not known. We therefore plan to undertake a study to evaluate current training provision, taking into account the deficiencies set out in a Collegiate Trainee's Committee survey of 1988 (Scott \& Webb, 1988) and the challenge for service provision set out in the NSF (Department of Health, 1999).

\section{Difficulties working in the community pose to the learning process}

Trainees look to their colleagues for emotional support and assistance with clinical work. Working at dispersed sites can result in increasing isolation from their peers and loss of this support (Davies \& Cox, 1996). One consequence of the dispersal of trainees is difficulty in attending academic meetings, which are usually held at central locations, often with restricted parking. Attendance may also be compromised by trainees' responsibilities to provide emergency cover at peripheral sites.

By its very nature community work involves travelling between sites, and trainees who do not have their own transport may be at a disadvantage. Furthermore, there are financial implications of increased travelling and trainees should be made aware of entitlements.

There are fundamental organisational differences between working on the ward and in the community. A ward-based job often does not lend itself to a rigid timetable. Much of the work on an acute admission ward involves reacting to events, such as admissions, discharges and disturbed behaviour. Although community work can equally involve reacting to urgent problems, planning the day will be of greater importance. Trainees may face particular difficulty in organising their diaries, especially coordinating with other members of the team, and they may need help in addressing this.

Some trainees, especially SHOs, have real difficulty in becoming involved in community work 
owing to frequent demands from in-patient units. In-patient demands should not always take priority, as this would seriously compromise educational opportunities open to the trainees in the community. Trainees are likely to need help managing the sometimes considerable tension between in-patient and community demands.

A further problem may arise from the policy in some areas of reserving community-based posts for more experienced trainees. This may produce the perception that predominantly ward-based skills are the core competencies for the trainee to learn. Clearly, the management of in-patients is still vitally important but a balance in training should be based on future roles and responsibilities, which will incorporate the ability to manage hospital and community simultaneously. Clinical tutors and educational supervisors need to evaluate these factors when considering both the posts trainees are selected to train in and their role when in those posts. A clear example of this is placing GP trainees in predominantly ward-based jobs, which bear little relationship to problems they will face in primary care.

Traditional medical attitudes and assumptions may be challenged by the approach of CMHTs. Trainees unfamiliar with such approaches may have difficulty adjusting and thus fail to appreciate fully the importance of community training. Through supervision and induction, the supervisor should attempt to define the expectations to be made of trainees, so that they are not left guessing where their responsibilities lie or what their educational objectives are.

\section{Learning and training methods}

\section{General training structure}

A variety of methods of learning are needed to meet the challenge set by shifting psychiatric practice. Johnston et al (1995) suggest that new residency programmes are not necessary, but that hospitalbased practice needs a shift in attitude if staff are to learn to work with partners 'in the field'. Brown et al (1993) suggest that many of the learning objectives of community psychiatry training can be achieved in the traditional setting of in-patient wards, outpatient clinics and emergency assessments. The Sainsbury Centre for Mental Health (1997) advocates a training framework that is patient-focused and both theory- and practice-based, with collaborative training with other disciplines. Factor et al (1988) found supervision of trainees in small groups to be a useful adjunct to one-to-one supervision. Group supervision may also improve peer support, which is frequently difficult to maintain in dispersed placements. They encouraged trainees to continue to see patients for longer-term care. The current training in 6- or 12-month rotational posts often removes this opportunity to see patients beyond a specific attachment and thus develop the skills necessary for long-term care. They also offered specific teaching sessions (up to 24) on aspects of community psychiatry. The College's guidance on SpR training states that "all schemes are required to provide an academic programme specifically for SpRs at a minimum frequency of the equivalent of one session weekly throughout the university term" (Royal College of Psychiatrists, 1998a). Local consideration should be given to setting up specific 'community' teaching sessions for SpRs, so that learning is not just 'on the job'. This would create additional advantages of enhancing peer support, which can be lacking with dispersed rotations, encouraging critical appraisal of particular service models and permiting debate of attitudes.

We suggest that rotations with suitable role models should be the cornerstone of change. Within these posts supervision of community work and the setting of clear learning objectives are necessary. For the reasons discussed above, we believe that, on balance, it is better for trainees to have exposure to community-oriented psychiatry early in their $\mathrm{SHO}$ career and for them explicitly to be made part of a community team. The level of involvement of trainees in CMHTs will need careful monitoring by clinical tutors and educational supervisors to ensure that it is appropriate to their level of experience and confidence. We do not feel that juniors should be completely shielded from community work, as they would then have to learn entirely new skills at SpR level. We would rather see good foundations built upon. Clinical tutors may decide to create separate community posts if local circumstances make it difficult for trainees to get suitable community experience. However, such experience in isolation from an in-patient commitment can potentially be artificial, as the trainee may fail to appreciate fully the difficult task of managing the integration of community and in-patient services.

Consideration should be given to psychiatric trainees undertaking general practice attachments, so that mental health issues can be seen from an alternative perspective. General medical confidence is increasingly important now that trainees work in isolated sites and that evaluation of physical problems is reflected in the MRCPsych examination. With this in mind, other hospital attachments should also be considered, as should the involvement of users and carers (Crawford \& Davies, 1998). 
The College's statement on approval of training schemes for basic specialist training for the MRCPsych (Royal College of Psychiatrists, 1998b) says that "community experience is essential, including domiciliary visits, home assessments with community nurses, occupational therapists or social workers and attachment in general practice". The College can strengthen this requirement via feedback on approval visits (Working Party of the Social and Community Psychiatry Section, 1982). College educational policy (Royal College of Psychiatrists, 1997) states that MRCPsych candidates should have detailed knowledge of the assessment of the need for psychiatric services within a community, and MRCPsych courses may have to be changed to reflect this.

\section{Specific changes in training}

Educational objectives for trainees will need to focus on specific areas of development. Psychotherapy training may need to embrace new therapeutic approaches, such as cognitive-behavioural therapy for psychosis and treatment-resistant depression, family interventions in schizophrenia and bipolar affective disorder, as well as maintaining training in traditional psychodynamic psychotherapy. Skills in the latter may need to take into account future progress in treating severe personality disorders, as these cause significant anxiety in CMHTs and inpatient units. To achieve a level of competency, coordinated psychotherapy training may need to extend beyond $\mathrm{SHO}$ training into $\mathrm{SpR}$ rotations.

Training courses in leadership, management, appraisal techniques, team building and negotiation skills should be seen to be as important as courses in clinical skills. Time with managers and trust executive board members should be encouraged. The experience of being involved in the development of a new service is invaluable. An experienced SpR may consider taking on partial responsibility for a defined sector under supervision. It would be invaluable for SpRs to visit different centres outside the normal rotation and to discuss their findings with peers. SHOs should accompany senior colleagues in the community as frequently as they attend inpatient ward rounds.

The role of mentorship throughout training must be reassessed. This could straddle rotations, helping to increase trainees' appreciation of the responsibilities of continuing care. Mentorship may be a less threatening learning environment than conventional supervision and it may provide a continuity of training that is lost when trainees change supervisors. Programme directors may wish to consider developing such systems locally. Such mentorship could, if necessary, be taken forward as an SpR makes the sometimes difficult transition into a consultant post. Recommendations for change are summarised in Box 2.

\section{Conclusions}

It is possible for junior doctors to remain in inpatient settings without ever becoming involved with CMHTs. This situation should be re-appraised in terms of their overall training needs and goals. There must be a wide variety of good placements in

Box 2 Recommendations for change

Each rotation should include community work at senior house officer and specialist registrar grades (in-patient demands should not detract from the community experience, but trainees must not be overprotected, as they must learn to manage competing demands)

College approval visits should offer direct feedback on the quality of community training

There should be opportunities to follow certain patients, under local supervision, beyond the duration of the specific attachment (perhaps for $2-3$ years)

Trainees at dispersed sites should have adequate face to face contact with supervisors and peers

The more junior the trainee is, the more supervision should be provided

Local group-teaching modules on community psychiatry incorporating inter-disciplinary learning should be offered

Case conferences and journal clubs should, on occasions, be open to the multidisciplinary team, and focus on longerterm care and trainees should be given adequate time to attend

General practitioner trainees should have greater access to community experience, rather than being predominantly hospitalbased

Research and audit should shift toward community models of care

Psychotherapy training should be re-evaluated to include interventions for those with severe mental illness 
which community training needs can be met. Within such posts greater imagination may be needed to make the most of the training experience.

Trainees need to learn the management skills they will need in senior posts, in managing themselves and others effectively. It is important that we equip ourselves with the requisite tools for our continual professional development, to enable us to both lead and sustain high-quality, diverse services.

The development of personal responsibility is even more important in dispersed community settings, where we deal with a variety of fellow professionals, carers and clients often without peer supervision. Trainees must develop the skills to address potential isolation, an increasing volume of work in too many locations and the seemingly conflicting demands between community and hospital work. New demands are likely continually to be made of medical staff, particularly as service delivery changes and new models of care and intervention develop. O'Grady (1996) concludes that there is a danger that the pace of change within mental health delivery will outstrip the ability of training systems to deliver the consultants of the future. The change to communityoriented psychiatry is a prime example of this and therefore presents the College, programme directors, clinical tutors, educational supervisors and trainees with a challenge to training management. They should all be encouraged to involve other disciplines to meet this challenge.

It is of fundamental importance that trainers have the opportunity to review their own training needs in community-oriented psychiatry, to establish whether their role should change within these developing services. There is a limit, however, to how much additional training can be absorbed by both the trainee and the training system. We may have to accept that we cannot prepare every doctor for every role. A rethink of the role and responsibilities of psychiatrists is therefore timely (Kennedy \& Griffiths, 2000). Crucially, a modern training programme needs to equip doctors with the ability continually to review their role in relation to the task ahead, particularly if they wish to maintain both their personal health and the health of the service.

Although this article indicates the need for additional training, which may sound daunting, we should remember that community psychiatry provides the opportunity to work outside the hospital and become familiar with the area served: an opportunity often denied non-psychiatric hospital doctors. It offers the chance to enjoy working with other disciplines, to explore preventive work and engage in non-hospital research. In short, our work can potentially become more stimulating and rewarding, if we learn to manage both ourselves and the service effectively.

\section{References}

Bancroft, J. (1986) Crisis intervention. In An Introduction to the Psychotherapies (ed. S. Bloch), pp. 113-132. Oxford: Oxford University Press.

Brown, D. B., Goldman, C. R., Thompson, K. S., et al (1993) Training residents for community psychiatric practice: guidelines for curriculum development. Community Mental Health Journal, 29, 271-283.

Crawford. M. \& Davies, S. (1998) Involvement of users and carers in the training of psychiatrists: making it happen. Psychiatric Bulletin, 22, 42-43.

Davies, S. \& Cox, J. (1996) Training on dispersed sites. Discussion paper from the Education Committee. Psychiatric Bulletin, 20, 33-35.

Dedman, P. (1993) Home treatment for acute psychiatric disorder (editorial). British Medical Journal, 306, 1359-1360.

Department of Health (1999) The National Service Framework for Mental Health. Modern Standards and Service Models. London: Department of Health.

Factor, R. M., Stein, L. I. \& Diamond, R. J. (1988) A model community psychiatry curriculum for psychiatric residents. Community Mental Health Journal, 24, 310-327.

Haddad, P. \& Creed, F. (1996) Skills training for senior registrars. Results of a survey of recently appointed consultants. Psychiatric Bulletin, 20, 391-394.

Johnston, M., Binder, T., Freeland, A., et al (1995) Suggestions for implementing community psychiatric training in existing residency programs. Canadian Journal of Psychiatry, $40,623-626$

Joy, C. B, Adams, C. E. \& Rice, K. (2000) Crisis intervention for people with severe mental illness. Cochrane Library, issue 1. Oxford: Update Software.

Kennedy, P. \& Griffiths, H. (2000) An Analysis of the Concerns of Consultant General Psychiatrists About their Jobs, and of the Changing Practices that May Point Towards Solutions. Durham: Northern Centre for Mental Health.

Kingdon, D. (1994) Making care programming work. Advances in Psychiatric Treatment, 1, 41-46.

Marshall, M. (1996) Case management: a dubious practice (editorial). British Medical Journal, 312, 523-524.

— \& Creed, F. (2000) Assertive community treatment - is it the future of community care in the UK? International Review of Psychiatry, 12, 191-196.

— \& Lockwood, A. (2000) Assertive community treatment for people with severe mental disorders. Cochrane Library, issue 3. Oxford: Update Software.

Muijen M. (1993) The consultant psychiatrist and community care. Psychiatric Bulletin, 17, 513-516.

O'Grady, J. C. (1996) Community psychiatry: central policy, local implementation (editorial). British Journal of Psychiatry, 169, 259-262.

Royal College of Psychiatrists (1997) Educational Policy. (Occasional Paper OC36), p. 21. London: Royal College of Psychiatrists.

— (1998a) Higher Specialist Training Handbook. (Occasional Paper OP43), p. 11. London: Royal College of Psychiatrists. - (1998b) Statement on Approval of Training Schemes for Basic Specialist Training for the MRCPsych (BSTC/01), p. 6. London: Royal College of Psychiatrists.

Sainsbury Centre for Mental Health (1997) Pulling Together. The Future Roles and Training of Mental Health Staff. London: Sainsbury Centre for Mental Health.

Scott, J. \& Webb, T. (1988) Training implications of the shift to community-orientated psychiatric services. Collegiate Trainees' Committee Working Party report. Bulletin of the Royal College of Psychiatrists, 12, 151-153.

Tarrier, N., Haddock, G. \& Barrowclough, C. (1998) Training and dissemination: research to practice in innovative psychosocial treatments for schizophrenia. In Outcome and Innovation in Psychological Treatment of Schizophrenia (eds T. Wykes, N. Tarrier \& S. Lewis), pp. 215-236. Chichester: John Wiley \& Sons. 
Tyrer, P. \& Creed, F. (1995) Community Psychiatry in Action: Analysis and Prospects. Cambridge: Cambridge University Press.

Vaddadi, K. S. (1997) Burden of care in the home: issues for community management. Advances in Psychiatric Treatment, 3, 146-153.

Working Party of the Social and Community Psychiatry Section (1982) Should community psychiatrists be specialists? Bulletin of the Royal College of Psychiatrists, $\mathbf{6}$, 190-194.

Wykes, T., Tarrier, N. \& Lewis, S. (1998) Innovation and outcome in psychological treatments for schizophrenia: the way ahead? In Outcome and Innovation in Psychological Treatment of Schizophrenia (eds T. Wykes, N. Tarrier \& S. Lewis), pp. 1-15. Chichester: John Wiley \& Sons.

\section{Multiple choice questions}

1. Training for SHOs should:

a be predominantly ward-based

b make safety a priority

c emphasise methods of community working

d follow patients for only short periods.

2. Community-oriented psychiatry:

a is practised solely by general adult psychiatrists

$b$ has well-defined models of intervention

c has no evidence base

d relies on good team work.
3. The move towards community-oriented psychiatry:

a does not radically affect the role of consultant psychiatrists

$\mathrm{b}$ requires a change in knowledge and skills but not in attitude

c has implications for programme directors and clinical tutors

d creates potential problems of isolation and time management.

$\begin{array}{llll}\text { MCQ answers } & & \\ & & & \\ \text { 1 } & \text { 2 } & & 3 \\ \text { a F } & \text { a F } & & \text { a F } \\ \text { b T } & \text { b T } & & \text { b F F } \\ \text { c T } & \text { c F } & \text { c T T } \\ \text { d F } & \text { d T } & & \text { d T }\end{array}$

\section{Psychiatry in Multicultural Britain} Edited by Dinesh Bhugra and Ray Cochrane

Cultural factors play a very important role in the way psychiatric symptoms are presented to clinicians and how clinicians deal with them. In this book practitioners from a range of ethnic backgrounds discuss cross-cultural psychiatry and offer theoretical and practical perspectives on its practice in multicultural Britain.

Although aimed at psychiatrists, this book will be of great interest to all health professionals including nurses, psychologists, social workers, general practitioners and occupational therapists.

\section{Features}

- Puts together theoretical and practical perspectives in dealing with mental health problems of Black and minority groups in a multicultural society.

- Provides an overview on the role of anthropology, racism, cultural identity and prejudice in development of individuals and development of psychiatric symptoms in vulnerable individuals.

March 2001, £30.00, ISBN 1901242455

To order copies please contact: Book Sales, Royal College of Psychiatrists, 17 Belgrave Square, London, SW1X 8PG. Tel: +44 (0)20 72352351 Ext 146. Fax: +44 (0)20 72451231. Credit card orders can be taken over the telephone. 